\title{
Reform of Ecology Teaching Based on the Specialty Characteristics of Landscape Architecture
}

\author{
Juan Chen ${ }^{1 *, a}$, Guojiao Yu ${ }^{1, b}$
}

\author{
${ }^{1}$ School of Urban and Rural Planning and Construction, Mianyang Normal University, Mianyang \\ 621000, China \\ a408234232@qq.com; b1851032439@qq.com \\ ${ }^{*}$ Corresponding author: Juan Chen
}

Keywords: Landscape architecture, Ecology teaching, Teaching reform, Questionnaire survey.

\begin{abstract}
Ecology is a comprehensive discipline involving natural science and humanities. Under the background of global economic development and national ecological civilization construction in China, ecology is facing with unprecedented challenges and opportunities. Landscape architecture is a specialty to cultivate application-oriented professionals who can meet the needs of the country and the industry in the new era as well as undertake the greening of urban and rural areas, rural revitalization and ecological civilization construction. The teaching of ecology is an important part of realizing the goal of talent cultivation of landscape architecture specialty. In this paper, through the questionnaire survey, literature review and the investigation of ecology teaching in colleges and universities at home and abroad, we analyzed the current situation of ecology teaching in the landscape architecture specialty. The results of the investigation pointed out that there are some problems in ecology teaching, such as too much emphasis on theory, lack of specialty features, weak practice teaching, single teaching and assessment methods, and low learning initiative of students. A series of measures of ecology teaching reform are put forward to improve the teaching effect and promote the sustainable development of ecology teaching in landscape architecture specialty.
\end{abstract}

\section{Introduction}

With the development of society and economy, the problems of population density, energy shortage and environmental pollution have made mankind suffer a $\operatorname{lot}^{[1,2]}$. Ecology is a science that studies the relationship between organisms and their surroundings. Human beings put forward the concepts of sustainable development and ecological civilization from the perspective of ecology. Ecology has become a key subject for human beings to improve the environment and realize sustainable development ${ }^{[2,3]}$. China's rapid economic development has exposed many environmental problems. Under the background of national rural revitalization and ecological civilization construction in the new era, more ecological talents are needed for support. Therefore, ecology teaching should become one of the important contents in many colleges and universities ${ }^{[3]}$. Landscape architecture specialty is aim to cultivate professional talents for garden plants breeding and cultivation, the landscape design, planning and construction of scenic spots, forest park and various urban landscape green space, as well as to serve for the national urbanization construction, rural revitalization, the construction of ecological and beautiful China ${ }^{[4]}$. At present, many colleges and universities have taken ecology as basic courses or compulsory courses in the talent training programs of landscape architecture specialty. In order to effectively inherit and develop ecological knowledge in college classrooms, improve the overall teaching level of ecology and promote the realization of professional talent training goals, the defects of current ecology teaching are pointed out through the questionnaire survey, comparative analysis of ecology teaching at home and abroad. Moreover, the ideas and specific measures of ecology teaching reform are put forward to promote the ecological teaching and to achieve the purpose of cultivating talents with ecological quality and concept combined with the professional characteristics of landscape architecture. 


\section{Questionnaire survey on ecology teaching in landscape architecture specialty}

\subsection{Research methods}

Taking the ecology teaching of landscape architecture specialty as the starting point, the students' feedback on the teaching contents, teaching methods and assessment methods of ecology course was understood by issuing questionnaires. A total of 172 questionnaires were issued and 157 valid questionnaires were recovered, with a recovery rate of $91.3 \%$.

\subsection{Results and analysis}

\subsubsection{Unclear course positioning and complex and repetitive teaching contents}

Ecology is a comprehensive science involving a wide range of fields. It is the foundation or subsidiary discipline of many majors. Some of its teaching contents were overlapped with soil geography and other disciplines. Therefore, it is helpful to make use of teaching resources reasonably to define curriculum orientation based on the objective of professional training. According to the survey, $76 \%$ students of landscape architecture believe that the chapters of the ecology course are somewhat repetitive with other courses. The reason is that the basic ecology and other related courses, such as landscape ecology, belong to the basic and applied research field of ecological discipline, and have internal connections. Therefore, it is necessary to integrate the teaching content of the two courses, so as to highlight the characteristics and teaching objectives of different courses. Secondly, the teaching content of ecological factors of individual ecology in ecology course and some chapters of plant physiology, soil science, garden plant cultivation and maintenance course also have certain repetition, which can be adjusted and refined together through the concentrated lesson preparation of relevant teachers.

\subsubsection{Obsolete course content and single teaching mode}

Investigating students' interest in ecology course chapters, $12 \%$ of students are interested in individual ecology, $16 \%$ of students are interested in population ecology, $17 \%$ of the students are interested in community ecology, $15 \%$ of students are interested in ecosystem ecology, 27\% of students are interested in landscape ecology, and 14\% of the students are interested in the global ecology. It can be seen that students have different interests, but higher interest in landscape ecology, which is more closely combined with the characteristics of landscape architecture specialty. According to the survey, $69 \%$ of the students believe that the teaching content of ecology course contains little information about the latest scientific research trends and achievements, and the teaching content needs to be updated. According to the survey, 29 percent of the students are satisfied with the teaching content and method of ecology, 50 percent are basically satisfied, and 20 percent are generally satisfied. However, the survey also shows that $85 \%$ of the students feel that the teaching content and method need to be improved, which indicates that most of the students are basically satisfied and agree that they have acquired ecological knowledge through learning, but still hope to further improve the teaching effect of ecology course. The $69 \%$ of the students thought that the reform of teaching methods in ecology could further improve students' enthusiasm and teaching effect. In the survey, $43 \%$ of the students indicated that the teaching methods and means of ecology courses they had received were mainly lecture, and the classroom teaching was not assisted by practical teaching, so most of the students could not deeply understand the essence of ecology theory. According to the survey, $73 \%$ of the students think that the teaching of ecology can properly strengthen the practical teaching and the cultivation of practical ability. In terms of network and online course construction of ecology, up to $64 \%$ of students think that it is appropriate to build network and online ecology course, and $27 \%$ of students think that it is necessary. In collecting students' suggestions about teaching methods, $11 \%$ of the students think ecology question guiding method can be used, $39 \%$ of students think case analysis can be used, $16 \%$ of students think that flip classroom teaching method can be used, $13 \%$ of students think that seminar teaching method can be used, $21 \%$ of students think that relevant video materials can be introduced in combination with specific chapter content. It can be seen that students are willing to try and accept various teaching methods. 


\subsubsection{Single assessment method and lack of comprehensive evaluation system}

At present, the ecology curriculum assessment is usually based on the traditional closed-book final examination combined with daily homework scores. According to the survey, $86 \%$ of the students think that the assessment system of ecology teaching can adjust the assessment types appropriately and add comprehensive assessment methods. Among them, $6 \%$ of the students think that this course assessment can adopt the way of close-book exam, 14\% of the students think they can adopt the way of an open-book exam, $25 \%$ of the students think of using appraisal way of combining practice with theory, $11 \%$ of the students think they can adopt the way of literature reading and monographs, $20 \%$ of students think that the course could be assessed through ecology internship and study, $12 \%$ of students think they can use the way of research reports, and $13 \%$ of students think they can use the way of classroom discussions and homework. It can be seen that constructing a scientific and reasonable evaluation system and diversifying the evaluation methods are also important contents of ecology teaching reform. Giving consideration to both theory and practice, combining scientifically evaluating students' course performance are conducive to students' changing learning attitude and adjusting learning methods.

\subsubsection{Investigation of students' learning interest and intention}

According to the survey, $51 \%$ of the students showed interest or high interest in the ecology course, while $48 \%$ of the students showed ordinary learning interest. The 46 percent of the students said they were earnest about studying ecology-related courses, while 53 percent said they were sometimes earnest and 1 percent said they were not earnest about studying. According to the survey, $86 \%$ of the students think it is worthwhile to learn ecology courses earnestly under the background of promoting ecological civilization construction. $70 \%$ of the students think the ecology courses have a degree of correlation and promotion effect with their specialty, and $27 \%$ think they have a significant correlation and promotion effect. However, the survey also showed that $71 \%$ of the students thought that the teaching of existing ecology-related courses in their specialty was not valued very much. According to the survey, 38 percent of the students said they can accept working in an ecology-related field, while 34 percent said they would be willing to work in the ecology-related field, The $53 \%$ of the students are very willing to participate in ecology-related scientific research or undergraduate innovation and entrepreneurship projects. The $55 \%$ of the students showed a strong willingness to use their knowledge of ecology to carry out ecological science popularization and ecological protection activities, and $43 \%$ said they could participate in relevant activities. It can be seen that students majoring in landscape architecture all recognize the importance of ecology teaching and its promoting role in professional learning. Therefore, in talent cultivation, ecological teaching should be emphasized and strengthened in combination with professional characteristics.

\section{Ecology teaching situation of landscape architecture specialty in universities}

Many universities at home and abroad have set up ecology courses in the undergraduate teaching of landscape architecture ${ }^{[5,6]}$. The undergraduate education of landscape architecture in the Illinois University attaches importance to the cognition of nature and ecology. The specialized courses of the Hong Kong University include ecological design and planning. The subject of landscape architecture in the Southeast University has the direction of landscape planning and ecological restoration, and its specialized basic courses include landscape ecology. The natural/humanistic theory module in the landscape architecture design major of the Chongqing University and Beijing Forestry University includes ecology and pays attention to the cultivation of ecological literacy. Landscape ecology is included in the basic courses of landscape architecture in Northeast Forestry University and other agricultural and forestry colleges ${ }^{[7,8]}$. Therefore, how to organically integrate and rationally position the ecology with interdisciplinary characteristics according to the specialty characteristics of landscape architecture has become the key link to improve the teaching effect of ecology and realize the cultivation goal of landscape architecture professionals. Although under the objective requirement of the development of new era, many universities have opened courses 
related to ecology, but most of the ecology teaching effect is not ideal. The reasons are as follows: the course positioning is un-rational and un-correct; the teaching method is not fit the strong theoretical feature of ecology; the indoctrination of theory is more emphasized, while the cultivation of practical ability has been neglected; the assessment method of course learning is not scientific and so on. Unfortunately, most science faculty in college, including ecologists, have little research on learning or its application to teaching. To help improve college ecology instruction, ecology faculty should design research about ecology teaching and ecological thinking ${ }^{[3]}$. In the ecology teaching of landscape architecture specialty, there is a disconnection between theoretical teaching and professional practice and other relevant courses. In fact, the breeding, cultivation and application of garden plants, landscape planning, design and engineering practice all contain the basic theories of ecology, but the students are less refined and lack the ability to combine theory with practice. On the background of rapid development of ecology and endless scientific research achievements, teaching cases in textbooks are relatively old and lack of introduction to hot research issues at home and abroad. Many colleges and universities do not pay enough attention to the course of ecology, for example, the teaching and research funds invested in the course are insufficient, and the teaching infrastructure and conditions are not perfect enough, so the relevant colleges and departments have no ability to build field practice bases and laboratories. In the process of teaching, teachers can only teach the theory, the class is boring, and students have difficulty in understanding, let alone innovation. However, some teachers made useful attempt to create several programs for ecology teaching, such as 'Restoration of Semi-natural Grassland' and 'Design of Educational Garden Highlighting the Problems with Alien Species'. In this way, new developments in ecology can be shared in professional landscape architecture ${ }^{[6]}$.

\section{Ideas and measures of ecology teaching reform}

\subsection{Ideas of ecology teaching reform}

Under the background of ecological consciousness popularizing all over the world, ecological reform should be people-oriented and pay more attention to the expansion of students' abilities of thinking, practice and innovation. The ecology teaching should implement the requirements of new agricultural discipline construction and the fundamental undergraduate education in our country' higher education, and promote the level of undergraduate education. Ecology teaching reform should be based on professional characteristics and personnel training objectives, starting from the teaching content, teaching methods, assessment and evaluation methods, practical teaching links, etc, to cultivate a lot of professionals with ecological concept and quality who can better work in garden plant management, landscape planning, design and construction as well as to meet the needs of national and industrial development.

\subsection{Specific measures of ecology teaching reform}

\subsubsection{Adjust teaching contents according to local and professional characteristics}

Ecological reform should highlight the specialty features of landscape architecture, and pay more attention to the integration of teaching content system. Ecology teaching should be combined with other major courses, so that basic theories of ecology and professional knowledge can be organically combined. On the premise of retaining necessary basic knowledge of ecology theory, the content of practical teaching should be enhanced to stimulate students' interest in learning and to cultivate their innovative consciousness. Ecology is a constantly developing discipline, therefore, the latest scientific research trends and achievements are indispensable in the course content ${ }^{[7]}$. That can not only expand students' scope of knowledge and improve their professional quality, but also guide students to thoroughly understand the principles of ecology, cultivate their awareness of scientific research and stimulate their interest in learning and autonomy. Ecology teaching should be rooted in and serve local areas. All theoretical knowledge comes from practice and is eventually fed back into practice. Therefore, our ecological education should also extract factors from local urban or rural construction to make the curriculum have certain regional characteristics. At the same time, 
with the help of the platforms of school-enterprise synergy, students can undertake some projects about ecological planning and design, ecological restoration and protection practices, and to apply what they have learned.

\subsubsection{Reform teaching methods and modes}

\subsubsection{Multimedia teaching equipped with problem guidance and student lecture method}

Ecology teaching should construct the comprehensive teaching methods. Through the way of multimedia animation and audio display, students can have a more intuitive understanding of abstract concepts. In the teaching of some theories, teachers can use relevant myths and legends, classical poetry or interesting topics to introduce knowledge points and arouse students' interest in learning. Documentary refers to video materials that select real people and events as subjects, which has certain literature significance. Documentary teaching can make the theoretical knowledge of ecology properly connect with life, let students feel ecological process in the natural environment, and realize the intuitive and interesting teaching by watching video ${ }^{[9]}$.

\subsubsection{Integration of case teaching and flip teaching}

Taking students as the main body can improve students' participation and learning initiative by combining with the methods of guidance, lecture and discussion about some realistic hot issues. The case teaching method should be paid more attention in ecology teaching. The classic ecological cases are selected for analysis, leading students to apply the theoretical knowledge they have learned to the cases and seek for argumentation in the cases ${ }^{[10]}$. In addition to choose classic experiment case, we should also pay attention to its modernity and effectiveness in combination with disciplines and professional development trend in the new period ${ }^{[10,11]}$. Combined reality environment problem and landscape architecture professional characteristics, the ecology teaching can choice and discuss some ecological restoration and ecological planning cases in urban and rural landscape construction, in order to make the students' knowledge system can keep pace with development of new era and innovation consciousness. At the same time, the analysis of practical cases can make students understand some obscure theories and flexibly apply them to professional practice. The reverse teaching, considered as the future education model, has received great attention recently ${ }^{[12]}$. The flip teaching should be introduced into the ecology teaching under the universities to enhance the innovation and initiative of students.

\subsubsection{Special lectures and introduction of expert teaching}

Special lecture teaching is an expression of the importance of a course in colleges and universities. By special topic lecture, teachers and students can attach importance to the course and make more positive study. At the same time, in special lectures, many experienced experts and professors bring unique insights about the prospect of ecological development at home and abroad, which will broaden students' horizon and benefit them a lot. The ecological wisdom and professional quality conveyed by experts can inspire students and stimulate their learning potential to some extent.

\subsubsection{Construction of online ecology courses}

Network and online courses are a supplement to face-to-face teaching and a way for students to get more learning resources. The construction of network courses will be conducive to the popularization of ecological knowledge and extend in-class teaching to out-of-class teaching.

\subsubsection{Strengthen practical teaching of ecology}

Firstly, the field teaching of ecology is one of the key problems in the reform of ecology and also the core of the optimization of teaching reform. Considering the safety of field teaching and the shortage of educational funds, field practice teaching has not been effectively implemented. Therefore, the field practice base is selected from the perspective of safety and ecological resources, to promote teachers to teach students knowledge from micro and macro aspects, and to encourage students to explore actively in the field practice. Secondly, combined with the specialty features of landscape architecture, relevant practical teaching activities concerning the structure and function of urban and rural landscape ecosystem can be carried out to combine theory with practice, stimulate students' creativity and autonomy, and make ecology teaching sustainable development. Thirdly, the cooperative education mechanism between the school and enterprises should be encouraged to strengthen students' practice ability by means of carrying out some project cooperation including 
the production and application of garden plants, landscape design and construction and so on. 4.2.4 Enrich the assessment methods and establish a comprehensive evaluation system It is an important content of ecology teaching reform to construct a scientific and reasonable evaluation system and to diversify the evaluation methods. Giving consideration to theory and practice, combining open book with closed book, and various methods such as literature reading, paper writing, research report and internship report should be comprehensively used to evaluate students' course performance scientifically.

\section{Conclusion}

The results of the questionnaire survey show that quite a few students majoring in landscape architecture are interested in ecology courses. However, the questionnaire survey and investigation of ecology teaching of universities at home and abroad also reflect that there are many problems in ecology teaching, such as too much emphasis on theory, lack of specialty features, weak practice teaching, single teaching method and assessment method, and low learning initiative of students. Therefore, in order to effectively improve the teaching effect of ecology and cultivate more excellent ecological talents, it is necessary to carry out ecological teaching reform. Combining the talent training objectives and professional characteristics of landscape architecture specialty, we should follow the latest research achievements of the development of ecology, integrate and optimize the teaching content combine with professional practice and other related professional courses. In this way, students can effectively master the theory and methods of ecology, cultivate professionals qualified landscape plant application and landscape planning and construction posts, and professional talents with ecological concept and quality that adapt to the national rural revitalization and ecological civilization construction.

\section{Acknowledgment}

This research was financially supported by the Fund Project of Sichuan Provincial Department of Education of China (Mnu-JY1668) and the Fundamental Research Fund of Mianyang Normal University (Mnu-JY18278).

\section{References}

[1] M. Hale. Approaches to ecology teaching: the educational potential of the local environment, Journal of Biological Education, vol. 20, pp.179-184, 1986.

[2] C.D. YU. Discussion and practice of sustainable development as the main line of ecology teaching, Education and teaching forum, pp. 145-14, 62016.

[3] C. D'Avanzo. Research on learning: potential for improving college ecology teaching,Frontiers in Ecology and the Environment, vol. 10, pp.533-540, 2003.

[4] R. Yang. Opportunities and challenges of Chinese landscape architecture discipline. Chinese landscape architecture, vol. 5, pp.18-19, 2011.

[5] L. M. Nordlund. Teaching ecology at university-Inspiration for change, Global ecology and conservation, vol. 7, pp. 174-182, 2016.

[6] Y. Sawada, A. L. Planning, Possibility of sharing education method of ecology in a professional graduate school of landscape architecture and horticulture, Japanese Journal of Ecology, 2016.

[7] T. Zhang. Design of a series of teaching materials for landscape architecture specialty.Journal of Architectural Education in Institutions of Higher Learning,vol. 21, pp. 29-34, 2012.

[8] R A. Francis. Mapping urban ecology education in the UK.Journal of Biological Education, pp. $1-9,2018$. 
[9] N. Miao. A teaching method of integrating nature documentary into ecology course forum on contemporary education, vol.32, pp.169-170, 2017.

[10] Y. YE, J, ZHANG, Z. QIN. Application of case teaching method in the course of ecological planning.Guangdong Agricultural Sciences, pp. 19, 2011.

[11] C. D'avanzo. Application of research on learning to college teaching: ecological examples, BioScience, vol.53, pp.1121-1128, 2003.

[12] Nguyen B, Yu X, Japutra A, et al. Reverse teaching: Exploring student perceptions of “flip teaching",Active Learning in Higher Education, vol. 17, pp. 51-61, 2016. 